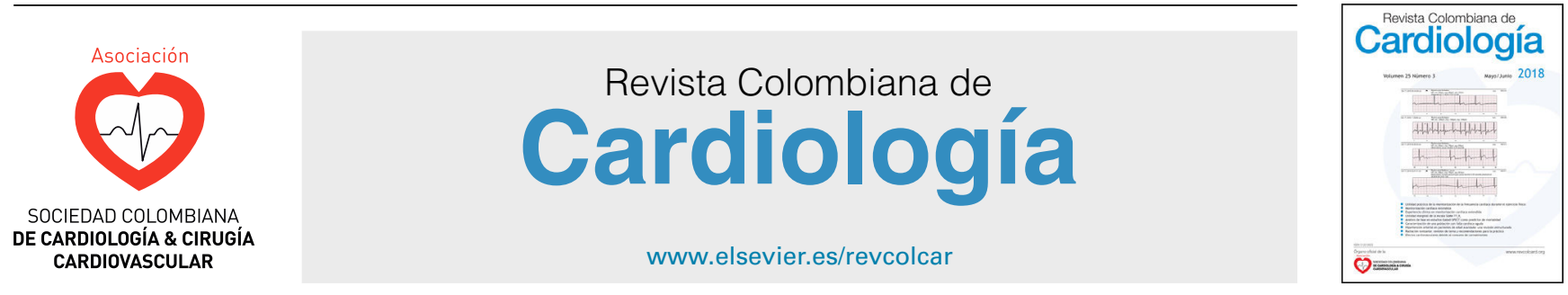

CARDIOLOGÍA DEL ADULTO - PRESENTACIÓN DE CASOS

\title{
Pericarditis constrictiva asociada a calcificación pericárdica extensa
}

\section{Álvaro Francisco Gudiño Gomezjurado*, Bianca Pujol Freitas y Flávia Contreira Longatto}

Instituto del Corazón INCOR. Universidad de São Paulo. São Paulo, Brasil

Recibido el 19 de enero de 2018; aceptado el 4 de abril de 2018

Disponible en Internet el 7 de junio de 2018

\section{PALABRAS CLAVE \\ Pericarditis \\ constrictiva; \\ Disnea; \\ Ascitis}

\section{KEYWORDS \\ Constrictive \\ pericarditis; \\ Dyspnoea; \\ Ascites}

\begin{abstract}
Resumen Se expone el caso de una paciente femenina de 39 años, con antecedente de disnea progresiva y eventos recurrentes de palpitaciones, en quien durante examen físico se observó ingurgitación yugular, ascitis de gran importancia y tercer ruido cardíaco compatible con "golpe pericárdico". Las pruebas de laboratorio mostraron niveles aumentados de péptido cerebral natriurético y titulación positiva de anticuerpos para el factor antinuclear. La radiografía de tórax mostró imagen radiopaca alrededor de la silueta cardiaca en patrón de "cáscara de huevo"'. La reconstrucción tomográfica evidenció calcificación pericárdica circunferencial difusa, incluida la pared miocárdica del ventrículo izquierdo y el músculo anteromedial papilar de la válvula mitral.

(C) 2018 Sociedad Colombiana de Cardiología y Cirugía Cardiovascular. Publicado por Elsevier España, S.L.U. Este es un artículo Open Access bajo la licencia CC BY-NC-ND (http:// creativecommons.org/licenses/by-nc-nd/4.0/).
\end{abstract}

\section{Constrictive pericarditis associated with extensive pericardial calcification}

Abstract It is presented the case of a 39 year-old female patient with a history of progressive dyspnoea and recurrent palpitation events. On physical examination jugular ingurgitation was observed, as well as a highly significant ascites, and heart sounds compatible with "pericardial knock'. The laboratory test results reported increased levels of brain natriuretic peptide and a positive antibody titre for antinuclear factor. The chest X-ray showed a radio-opaque image around the cardiac outline in an "egg shell pattern". The computed tomography reconstruction showed evidence of a diffuse calcification of the pericardial circumference, including the myocardial wall of the left ventricle and the antero-medial papillary muscle of the mitral valve. (C) 2018 Sociedad Colombiana de Cardiología y Cirugía Cardiovascular. Published by Elsevier España, S.L.U. This is an open access article under the CC BY-NC-ND license (http:// creativecommons.org/licenses/by-nc-nd/4.0/).

* Autor para correspondencia.

Correo electrónico: 584alvaro@gmail.com (Á.F. Gudiño Gomezjurado). 


\section{Introducción}

La pericarditis constrictiva es una enfermedad inflamatoria del pericardio de etiología variada que, en su forma más extrema, puede manifestarse por la presencia de calcificaciones pericárdicas y miocárdicas extensas.

Se presenta el caso de una paciente referida a nuestra unidad por presentar una extensa calcificación pericárdica y diagnóstico de dos años de evolución de aparente hepatopatía autoinmune.

\section{Caso}

Paciente femenina de 39 años, con historia de consumo de alcohol (aproximadamente $20 \mathrm{~g}$ al día por veinte años) y presumible enfermedad hepática crónica autoinmune diagnosticada dos años atrás.

Seis meses antes de la admisión presentó disnea progresiva y eventos recurrentes de palpitaciones. El examen físico reveló turgencia yugular, ascitis de gran importancia, tercer ruido cardíaco compatible con "golpe pericárdico" y soplo sistólico en el foco tricúspide de intensidad 2/6.

En la radiografía de tórax se evidenció imagen radiopaca alrededor de la silueta cardiaca en patrón de "cáscara de huevo" compatible con calcificación pericárdica difusa y derrame pleural bilateral (fig. 1). El electrocardiograma de 12 derivaciones demostró alteración difusa inespecífica de la repolarización ventricular.

Las pruebas de laboratorio mostraron aumento moderado de los niveles de péptido natriurético cerebral $(257 \mathrm{pg} / \mathrm{ml})$ y los títulos de anticuerpos antinucleares tuvieron títulos de

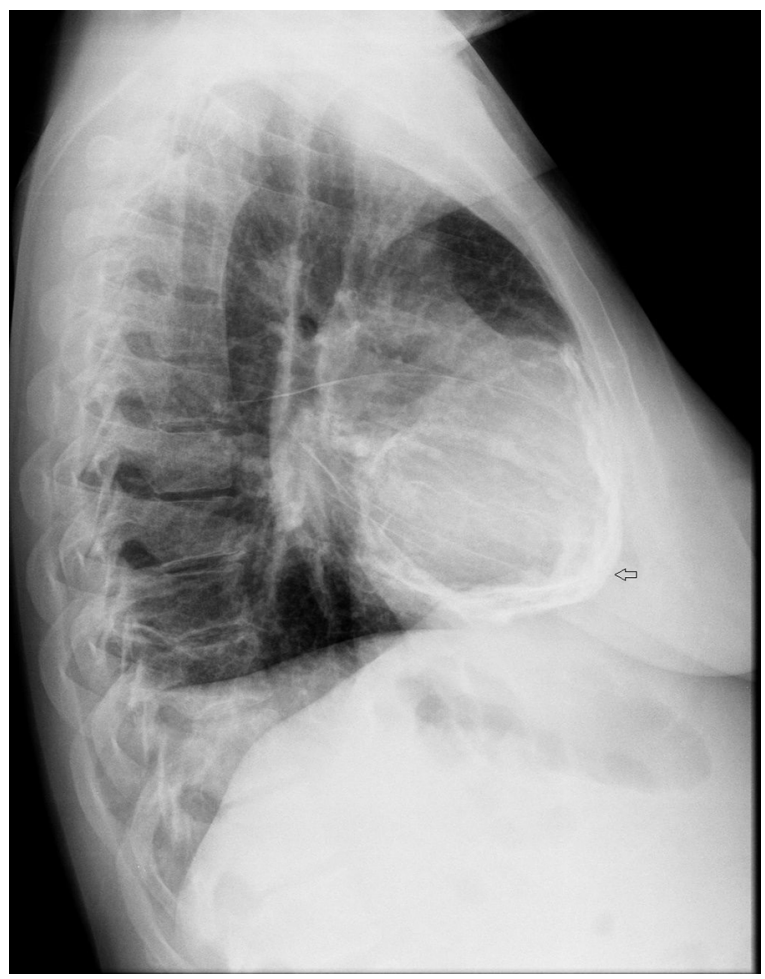

Figura 1 Radiografía lateral de tórax que muestra calcificación pericárdica difusa.

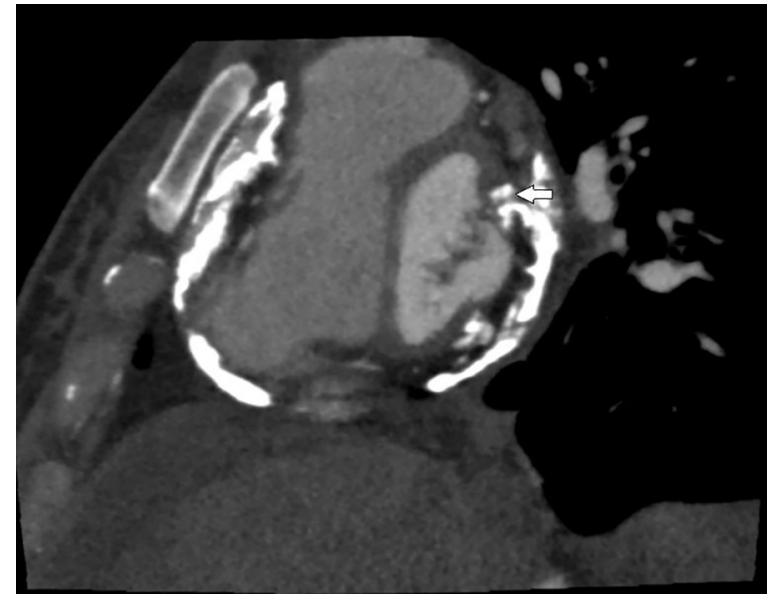

Figura 2 Tomografía computarizada de tórax con calcificación pericárdica difusa y compromiso de la válvula mitral.

$1 / 1280$ con un patrón nuclear moteado fino. La prueba cutánea de tuberculina (PPD) tuvo un diámetro de induración menor a $5 \mathrm{~mm}$.

El ecocardiograma transtorácico reportó aumento del tamaño biauricular, ausencia de disfunción, alteraciones segmentarias o engrosamiento de las paredes del ventrículo izquierdo e hipocinesia difusa del ventrículo derecho. No fue posible realizar el análisis de la función diastólica ventricular.

El estudio doppler de la válvula mitral demostró insuficiencia mitral de grado discreto (jet de regurgitación excéntrico).

Otros hallazgos fueron la presencia de engrosamiento del pericardio en la pared posterior y dilatación de la vena cava inferior sin colapsabilidad durante las maniobras respiratorias.

En ecografía abdominal se observó hígado con características normales y ascitis abdominal abundante.

La angiotomografía cardiaca reportó calcificación pericárdica circunferencial difusa con calcificaciones en la pared miocárdica del ventrículo izquierdo, incluyendo el músculo anteromedial papilar de la válvula mitral. El estudio de las arterias coronarias fue normal y el score de calcio fue de cero (figs. 2 y 3 ).

La paciente fue sometida a una pericardiectomía subtotal con preservación del pericardio de la cara diafragmática.

El examen histopatológico del pericardio mostró fibrosis y calcificaciones intensas con señales de metaplasia osea a nivel del tejido conjuntivo submesotelial. No se evidenciaron formaciones granulomatosas. La investigación histoquímica para hongos, bacterias y bacilos alcohol-ácido resistentes fueron negativas (métodos de Grocott, BrownHopps y de Ziehl-Nielsen).

\section{Discusión}

La pericarditis constrictiva es una enfermedad inflamatoria caracterizada por fibrosis o calcificación difusa del pericardio. Su etiología es variada y puede estar relacionada con procesos infecciosos (fúngicos, virales o bacterianos), por enfermedades del tejido conectivo, historia de trauma torácico, exposición a radiación, uremia, cirugía cardiaca 


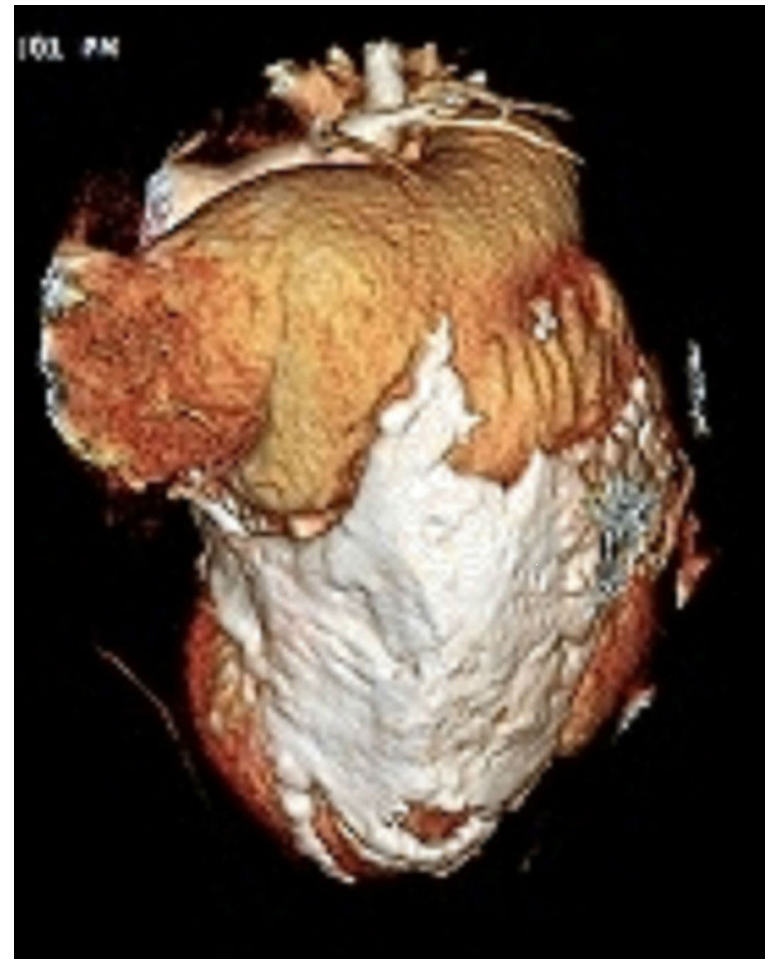

Figura 3 Reconstrucción tridimensional cardiaca en la que se evidencia la calcificación pericárdica con compromiso miocárdico del ventrículo izquierdo.

previa o, como en el caso expuesto, sin causa específica y por tanto catalogada como idiopática ${ }^{1-3}$.

El tiempo de desarrollo de esta enfermedad es variable y puede evolucionar en algunas semanas o llevar varios años, de acuerdo con el agente causal ${ }^{1,2,4}$.

La evolución clínica se caracteriza por disnea progresiva, elevación del pulso yugular, congestión hepática o ascitis $^{1,2,4}$. Desde el punto de vista fisiopatológico, estos signos y síntomas se atribuyen a disfunción ventricular derecha por disminución de la precarga y alteración progresiva del llenado ventricular ${ }^{2,4}$.

La principal manifestación radiológica son las calcificaciones pericárdicas que se dan entre el 5 y el $27 \%$ de los casos. En cuanto a morfología, se caracterizan por ser círculos de calcio amorfos e irregulares, depositados preferentemente a nivel del surco atrioventricular o en la cara diafragmática del corazón ${ }^{1,5}$.

Respecto a las calcificaciones pericárdicas, es importante considerar que el $30 \%$ de los pacientes con calcificaciones pericárdicas pueden presentar signos de pericarditis constrictiva y sólo el $50 \%$ de los pacientes diagnosticados con pericarditis constrictiva se manifiestan con calcificaciones pericárdicas obvias, de modo que, la ausencia o la presencia de este hallazgo no sirve para confirmar o descartar el diagnóstico de constricción pericárdica ${ }^{2,6}$.

En el caso de las calcificaciones miocárdicas, estas pueden ser secundarias a enfermedades infecciosas (tuberculosis, infecciones virales o micóticas), eventos isquémicos previos, insuficiencia renal crónica, trauma o radiación ${ }^{5,7}$. Sin embargo, como en el caso de las calcificaciones pericárdicas, la mayoría de ellas no tienen una causa específica y se consideran idiopáticas ${ }^{5,7}$.

El ecocardiograma mostró espesamiento de la pared posterior del pericardio, que generalmente es una constatación común en estos casos, aunque el $20 \%$ de los pacientes con diagnóstico de pericarditis constrictiva por ecocardiografía, pueden presentar un pericardio morfológicamente normal después de la cirugía ${ }^{8}$.

Se usó angiotomografía cardiaca para definir la extensión de la calcificación pericárdica antes de la cirugía, pero a diferencia de los casos descritos en la literatura, también se empleó para descartar enfermedad coronaria9?.

Con relación al péptido natriurético cerebral, se pudo evidenciar un aumento discreto de los valores de este marcador, lo cual tuvo relación con el diagnóstico de pericarditis constrictiva ya que, a diferencia de la miocardiopatía restrictiva, los niveles de péptido natriurético cerebral en esta patología suelen estar más elevados ${ }^{10,11}$. En lo concerniente a fisiopatología, la liberación de péptido natriurético cerebral depende del grado de estiramiento de las fibras musculares, por lo que en el caso de la pericarditis constrictiva, este fenómeno se ve limitado por el engrosamiento pericárdico y de esta manera se negativiza el estímulo de liberación de este biomarcador $^{12}$.

Finalmente, un aspecto que llama la atención en este caso es que la paciente fue diagnosticada de enfermedad hepática autoinmune por la presencia de anticuerpos antinucleares positivos. Se debe considerar que hasta el $3 \%$ de la población puede tener títulos falsos positivos y los patrones microscópicos, nucleolar o centromérico, son menos específicos para este tipo de enfermedad. Por tanto, la pericarditis constrictiva debe formar parte del diagnóstico diferencial de pacientes con sospecha de enfermedad hepática crónica manifestada con síndrome ascítico incluso con marcadores inmunológicos positivos ya que como queda demostrado en este caso, la positividad de anticuerpos antinucleares fue un resultado falso positivo $^{13,14}$.

\section{Conclusiones}

La pericarditis constrictiva es una enfermedad relativamente común en nuestro medio y debe ser tomada en consideración como parte del diagnóstico diferencial de pacientes con síndrome ascítico de causas no bien definidas.

A pesar de los avances tecnológicos en los métodos diagnósticos, todavía muchos casos se clasifican como idiopáticos. Sin embargo, en nuestro medio, las causas infecciosas, en especial la tuberculosis, deben ser la primera opción diagnóstica en pacientes con calcificaciones pericárdicas difusas.

Clásicamente, la tomografía cardiaca se ha utilizado para determinar la extensión de la calcificación pericárdica. Sin embargo, en este caso particular, también se utilizó para descartar enfermedad coronaria. Por tanto, la angiotomografía cardíaca podría ser utilizada como método diagnóstico para descartar enfermedad arterial coronaria en pacientes con calcificaciones cardíacas difusas y baja probabilidad clínica pretest. 


\section{Financiación}

Ninguna.

\section{Conflictos de intereses}

Ninguno.

\section{Bibliografía}

1. Vijayvergiya R, Vadivelu R, Mahajan S, Rana SS, Singhal $M$. Eggshell calcification of the heart in constrictive pericarditis. World J Cardiol. 2015;7:579-82, http://dx.doi.org/ 10.4330/wjc.v7.i9.579.

2. Nguyen T, Phillips C, Movahed A. Incidental findings of pericardial calcification. World Clin Cases. 2014;2:455-8, http://dx.doi.org/10.12998/wjcc.v2.19.455.

3. Ferguson EC, Berkowitz EA. Cardiac and pericardial calcifications on chest radiographs. Clin Radiol. 2010;65:685-94, http://dx.doi.org/10.1016/j.crad.2009.12.016.

4. Gautam MP, Gautam S, Sogunuru G, Subramanyam G. Constrictive pericarditis with a calcified pericardial band at the level of left ventricle causing mid-ventricular obstruction. BMJ Case Rep. 2012:2012, http://dx.doi.org/10.1136/bcr.09.2011.4743.

5. Ramesh G, Lawrence B. Calcifications of the heart. Radiol Clin North Am. 2004;42:603-17.

6. Kameda Y, Funabashi N, Kawakubo M, Uehara M, Hasegawa $H$, Kobayashi $Y$, et al. Heart in an eggshell-eggshell appearance calcified constrictive pericarditis demonstrated by three-dimensional images of multislice computed tomography. Int J Cardiol. 2007;120:269-72.
7. Shackley BS, Nguyen TP, Shivkumar K, Finn PJ, Fishbein MC. Idiopathic massive myocardial calcification: a case report and review of the literature. Cardiovasc Pathol. 2011;20:79-83, http://dx.doi.org/10.1016/j.carpath.2010.04.004.

8. Lee MS, Choi JH, Kim YU, Kim SW. Ring-shaped calcific constrictive pericarditis strangling the heart: a case report. International J Emerg Med. 2014;7:40, http://dx.doi.org/ 10.1186/s12245-014-0040-5.

9. Dweck MR, Williams MC, Moss AJ, Newby DE, Fayad ZA. Computed tomography and cardiac magnetic resonance in ischemic heart disease. J Am Coll Cardiol. 2016;68:2201-16, http://dx.doi.org/10.1016/j.jacc.2016.08.047.

10. Kapoor PM, Aggarwal V, Chowdhury U, Choudhury M, Singh SP, Kiran U. Comparison of B-type natriuretic peptide and left ventricular dysfunction in patients with constrictive pericarditis undergoing pericardiectomy. Ann Card Anaesth. 2010;13:123-9, http://dx.doi.org/10.4103/0971-9784.62942.

11. Parakh N, Mehrotra S, Seth S, Ramakrishnan S, Kothari SS, Bhargava B, et al. NT pro B type natriuretic peptide levels in constrictive pericarditis and restrictive cardiomyopathy. Indian Heart J. 2015;67:40-4, http://dx.doi.org/10.1016/ j.ihj.2015.02.008.

12. Leya FS, Arab D, Joyal D, Shioura KM, Lewis BE, Steen LH, et al. The efficacy of brain natriuretic peptide levels in differentiating constrictive pericarditis from restrictive cardiomyopathy. J Am Coll Cardiol. 2005;45:1900-2.

13. Kumar Y, Batia A, Minz R. Antinuclear antibodies and their detection methods in diagnosis of connective tissue diseases: A Journey Revisited. Diagnostic Pathology. 2009;4:1, http://dx.doi.org/10.1186/1746-1596-4-1.

14. Wettstein M, Häussinger D. Pericarditis constrictivaeine Differential diagnose be therapierefraktärem Aszites. Dtsch. Med. Wschr. 2000;125:1462-5. 